Indo. J. Chem. Res., 2018, 6(1), 22-25

\title{
UJI AKTIVITAS ANTIOKSIDAN DARI EKSTRAK BUAH KAWISTA (Limonia Acidissima) MENGGUNAKAN SPEKTROFOTOMETER UV-VIS
}

\author{
Antioxidant Activity Test From Fruit Extract Kawista (Limonia acidissima) \\ Using Uv-Vis Spectrofotometer
}

\author{
Waode Rustiah $^{1^{*}}$, Nur Umriani ${ }^{2}$ \\ ${ }^{I}$ Department of Chemistry, Faculty of Mathematics and Natural Sciences, Hasanuddin University \\ ${ }^{2}$ Study Program of Health Analyst, Academy of Health Analyst Muhammadiyah Makassar-Indonesia \\ *Corresponding author: waoderustiah79@gmail.com
}

Received: May 2018 Published: July 2018

\begin{abstract}
Antioxidant activity test has been done from kawista fruit. This study aims to determine the antioxidant activity of kawista based on the test using UV-Vis spectrophotometer conducted wavelength $(\lambda) 516 \mathrm{~nm}$. The kawista fruit is extracted by reflux using methanol solvent. The extracts were made at concentrations of $50 \mathrm{ppm}, 100$ ppm, $150 \mathrm{ppm}, 200 \mathrm{ppm}$ and $250 \mathrm{ppm}$. The results showed that the antioxidant activity based on $\mathrm{IC}_{50}$ values obtained on kawista fruit extract samples had a concentration of $1275 \mathrm{mg} / \mathrm{ml}$. The results obtained are at the level of $\mathrm{IC}_{50}>150 \mu \mathrm{g} / \mathrm{ml}$, this indicates that the kawista fruit have weak antioxidant ability.
\end{abstract}

Keywords: Kawista (Limonis acidissima), antioxidant, activity, $I C_{50}$, DPPH, extract.

\section{PENDAHULUAN}

Salah satu pemanfaatan tumbuhan adalah sebagai sumber vitamin. Vitamin merupakan zat pengatur yang meskipun jumlah yang dibutuhkan sangat sedikit, tetapi harus ada agar system metabolism tubuh dapat seimbang (Frei, 1994; Sediaoetama, 2008). Jika vitamin tidak terdapat dalam tubuh atau tidak memenuhi kebutuhan normal tubuh, maka seseorang dikatakan menderita hipovitaminosa (Frei, 1994; Sediaoetama, 2008).

Belakangan ini, antioksidan alami yang berasal dari tanaman herbal menjadi pilihan masyarakat (Ji dkk., 2004; Li dkk., 2011, Rustiah dkk, 2018). Beberapa tanaman telah banyak digunakan sebagai antioksidan alami (Thomas, 2009), sebagai obat tradisional untuk pengobatan penyakit infeksi, salah satunya adalah buah kawista (Limonia acidissima) yang berasal dari kabupaten Bima, yang secara empiris berkhasiat sebagai penurun panas, tonikum, sakit perut dan sebagai antioksidan. Aktivitas antioksidan dipengaruhi oleh komponen kimia dalam buah. Komponen kimia tersebut dipengaruhi oleh tingkat kematangan dari buah tersebut. Selain berpotensi sebagai antioksidan, buah kawista juga berpotensi sebagai antidiabetes, serta daun kawista berpotensi sebagai anti hepatoprotektif (Nugroho, 2012).

Antioksidan dapat menangkap radikal bebas dan mendetoksifikasinya. Antioksidan merupakan senyawa pemberi elektron (elektron donor) atau reduktan. Senyawa ini memiliki berat molekul kecil, tetapi mampu menginaktivasi berkembangnya reaksi oksidasi, dengan cara mencegah terbentuknya radikal. Radikal bebas adalah atom atau molekul yang tidak stabil dan sangat reaktif karena mengandung satu atau lebih elektron tidak berpasangan pada orbital terluarnya. Radikal bebas akan bereaksi dengan molekul di sekitarnya untuk memperoleh pasangan elektron supaya mencapai kestabilan atom atau molekul. Reaksi ini akan berlangsung terus menerus dalam tubuh dan bila tidak dihentikan akan menimbulkan berbagai penyakit seperti kanker, jantung, katarak, penuaan dini, serta penyakit degeneratif lainnya. Oleh karena itu tubuh memerlukan suatu substansi penting, yaitu antioksidan yang mampu menangkap radikal bebas tersebut sehingga tidak dapat menginduksi suatu penyakit (Kikuzaki and Nakatani 1993) 
Antioksidan juga merupakan senyawa yang dapat menghambat reaksi oksidasi, dengan mengikat radikal bebas dan molekul yang sangat reaktif. Akibatnya, kerusakan sel akan dihambat (Halliwel, 1999; Winarsi dkk., 2003). Berdasarkan asalnya, terdapat dua macam antioksidan, yaitu antioksidan alami dan antioksidan sintetik. Tubuh manusia tidak mempunyai cadangan antioksidan dalam jumlah berlebih, sehingga jika terdapat radikal berlebih, maka tubuh membutuhkan antioksidan eksogen. Adanya kekhawatiran akan kemungkinan efek samping yang belum diketahui dari antioksidan sintetik, menyebabkan antioksidan alami menjadi alternatif yang sangat dibutuhkan. Antioksidan alami mampu melindungi tubuh terhadap kerusakan yang disebabkan spesies oksigen reaktif, mampu menghambat terjadinya penyakit degenaratif serta mampu menghambat peroksida lipid pada makanan. Meningkatnya minat untuk mendapatkan antioksidan alami terjadi beberapa tahun terkahir ini (Sayuti dan Rina, 2015).

Aktivitas antioksidan memiliki hubungan yang linier positif dengan kandungan fenol di dalam ekstrak buah kawista (Nugroho, 2012). Senyawa fenol terutama asam fenolat dan flavanoid merupakan antioksidan alami di dalam buah, sayur, dan tanaman lain (Kahkonen et al., 1999; Prior et al., 2005; Rohman dkk., 2006; Tryasmono, dkk., 2016). Aktivitas antioksidan diukur berdasarkan peredaman warna ungu. Dimana ketika larutan DPPH dicampur dengan bahan antioksidan, maka akan terjadi reaksi penangkapan hydrogen yang berasal dari antioksidan oleh DPPH yang akan diubah menjadi 1,1 difenil-2-pikrihidrazil dan ditandai dengan perubahan warna dari ungu ke kuning. Adapun parameter aktivitas antioksidan adalah nilai $\mathrm{IC}_{50}$ (50\% Inhibytor concentration), yang diperoleh dari persamaan regresi (Molineux, 2004). Penelitian ini dilakukan untuk mengetahui aktivitas antioksidan dari buah kawista berdasarkan metode pengikatan radikal bebas, diphenyl picryl hidrazil (DPPH) secara spektrofotometri UV-Vis, berdasarkan atas nilai $\mathrm{IC}_{50}$.

\section{METODOLOGI}

\section{Pengambilan dan pengolahan sampel}

Sampel yang digunakan adalah sampel buah kawista yang berasal dari kota Bima. Sampel buah kawista dicuci kemudian ditiriskan, dipotong-potong kecil, selanjutnya dikeringkan di bawah sinar matahari langsung, kemudian setelah kering, lalu dibawa ke laboratorium untuk dilanjutkan ekstraksi.

\section{Ekstrak buah kawista dengan metode Refluks}

Ekstrak buah kawista (Limonia acidissima) dibuat dengan menggunakan alat refluks dengan pelarut methanol. Sampel ditimbang sebanyak kurang lebih 200 gram, dimasukkan ke dalam labu alas bulat dan ditambahkan pelarut organic yaitu methanol, hingga sampel terendam kurang lebih $2 \mathrm{~cm}$, diatas permukaan sampel atau 2/3 dari volume labu alas bulat, kemudian labu alas bulat dipasang kuat pada statif dan pada waterbath, lalu kondensor dipasang pada labu alas bulat yang dikuatkan dengan klem dan statif. Aliran air dan pemanas (waterbath) dijalankan sesuai dengan suhu pelarut yang digunakan. Setelah 4 jam dilakukan penyaringan. Filtratnya ditampung pada wadah penampung dan ampasnya ditambahan lagi dengan pelarut, dan dikerjakan seperti diawal, ekstraksi dilakukan selama 3-4 jam. Filtrat yang diperoleh dikumpulkan dan dipekatkan dengan vakum rotavapor sampai diperoleh ekstrak kental.

\section{Pengujian aktivitas antioksidan menggunakan DPPH}

Ditimbang ekstrak masing-masing sebanyak $10 \mathrm{mg}$, kemudian ditambahkan $10 \mathrm{~mL}$ methanol dan disonikasi selama 15 menit. Selanjutnya, sampel dan standard dipipet sebanyak 10, 20, 30, 40 dan $50 \mu \mathrm{L}$ dan dimasukkan ke dalam vial, kemudian ditambahkan methanol hingga $5 \mathrm{~mL}$. Dari masing-masing konsentrasi, dipipet $1,5 \mathrm{~mL}$ dan dimasukkan ke dalam vial yang berbeda, kemudian ditambahkan 1,5 mL larutan DPPH $0,04 \mathrm{mg} / \mathrm{mL}$. Vial didiamkan selama 30 menit, agar reaksi berjalan optimum, dihindarkan dari kontak langsung dengan cahaya. Selanjutnya diukur serapannya dengan spektrofotometer UVVis pada panjanggelombang $(\lambda) 516 \mathrm{~nm}$.

Kemudian dilanjutkan pembuatan larutan pembanding/control positif, yang digunakan adalah vitamin $\mathrm{C}$ dengan variasi konsentrasi yaitu 2, 4, 6, 8 dan $10 \mathrm{ppm}$. Setelah semuanya siap, dilakukan penentuan aktifitas antioksidan. Larutan baku dan larutan uji masing-masing dipipet sebanyak 1,0 $\mathrm{ml}$, dimasukkan ke dalam vial yang diluarnya ditutupi aluminium foil. Kemudian ditambahkan 4,0 ml larutan DPPH 40 
ppm, dikocok hingga homogen dan dibiarkan selama 30 menit. Selanjutnya diukur serapannya dengan spketrofotometer UV-Vis pada panjanggelombang $(\lambda) 516 \mathrm{~nm}$. Sebelumnya dilakukan pengujian blanko dengan cara memipet sebanyak 1,0 ml etanol dan 4,0 ml larutan DPPH 40 ppm, dikocok dan dibiarkan selama 30 menit, lalu diukur serapannya dengan spektrofotometer UV-Vis.

\section{Pengumpulan dan Analisis Data}

Data penelitian dikumpulkan dan diuji aktivitas antioksidan menggunakan rumus :

$$
\% \text { Pengikatan DPPH }=\frac{(\text { A Blanko }- \text { A Sampel })}{A \text { Blanko }} \times 100 \%
$$

Keterangan :

A blanko $=$ Absorbansi blanko

A sampel $=$ Absorbansi sampel

\section{HASIL DAN PEMBAHASAN}

Berdasarkan hasil penelitian yang telah dilakukan tentang uji aktivitas antioksidan buah kawista (Limonia acidissima) dengan metode DPPH secara spektrofotometri UV-Vis, maka didapatkan hasil seperti pada Tabel 1. Metode DPPH merupakan metode yang paling sering digunakan untuk menguji aktivitas antioksidan suatu tanaman. Antioksidan merupakan senyawa pemberi electron (elektron donor) yang berperan dalam menghambat oksidasi yang diperantarai oksigen.

Analisis pada penelitian ini dilakukan dengan menggunakan instrument spektrofotometer UV-Vis, yang diukur pada panjanggelombang $(\lambda) 516 \mathrm{~nm}$, karena sederhana, mudah dalam pengerjaannya, cepat, akurat dan hanya memerlukan sedikit sampel, serta cocok digunakan untuk analisis sampel yang memiliki kemampuan sebagai senyawa antioksidan. Pengujian aktivitas antioksidan dilakukan berdasarkan metode DPPH, karena cepat dan efektif untuk memperkirakan aktivitas antiradikal dari suatu senyawa, dimana ketika larutan DPPH dicampur dengan bahan antioksidan, maka akan terjadi reaksi penangkapan hidrogen yang berasal dari antioksidan oleh DPPH yang akan diubah menjadi 1,1 difenil-2-pikrihidrazil dan ditandai dengan perubahan warna dari ungu ke kuning (Molineux, 2003).
Vitamin $\mathrm{C}$ memiliki aktivitas antioksidan lebih kuat dibanding ekstraknya. Ekstrak buah kawista memiliki kandungan kimia yang berkhasiat sebagai tonikum, menurunkan panas. Selain itu, vitamin $\mathrm{C}$ juga bermanfaat menjaga ketahanan tubuh terhadap penyakit infeksi racun, antioksidan dan menurunkan kolesterol.

Tabel 1. Hasil pengukuran, presentasi pengikatan DPPH dan nilai $\mathrm{IC}_{50}$ dari ekstrak methanol buah kawista dan pembanding vitamin $\mathrm{C}$

\begin{tabular}{cccc}
\hline Sampel & $\begin{array}{c}\text { \% pengikatan } \\
\mathbf{D P P H}\end{array}$ & $\begin{array}{c}\mathbf{I C}_{\mathbf{5 0}} \\
(\mathbf{p p m})\end{array}$ & $\begin{array}{c}\text { Nilai } \\
\mathbf{I C}_{\mathbf{5 0}} \\
(\mathbf{p p m})\end{array}$ \\
\hline & 2,27 & & Sangat \\
Vitamin C & 3,48 & & Kuat \\
& 6,75 & 22,85 & $<50 \mathrm{ppm}$ \\
& 18,90 & & \\
Ekstrak & 8,60 & & \\
Buah & 0,33 & & Lemah \\
Kawista & 3,31 & & \\
(Limonia & 4,42 & 1275 & $>150 \mathrm{ppm}$ \\
acidissima) & 6,50 & & \\
\hline
\end{tabular}

Aktivitas antioksidan ditunjukkan dengan nilai $\mathrm{IC}_{50}$. Dimana nilai $\mathrm{IC}_{50}$ menyatakan besarnya konsentrasi larutan sampel (ekstrak ataupun vitamin C) yang dibutuhkan untuk mereduksi radikal bebas DPPH sebesar 50\%. Zat yang mempunyai aktivitas antioksidan tinggi, akan mempunyai nilai $\mathrm{IC}_{50}$ yang rendah. Hasil uji aktivitas antioksidan pembanding, yaitu vitamin $\mathrm{C}$, berada pada kisaran nilai $\mathrm{IC}_{50}$ dibawah $50 \mathrm{ppm}$, yaitu sebesar $22,85 \mathrm{mg} / \mathrm{ml}$. Hasil nilai yang didapatkan, dikategorikan sangat kuat dalam kemampuannya sebagai antioksidan.

Setelah dilakukan pengujian, diperoleh bahwa ekstrak methanol buah kawista (Limonia accidissima) memiliki kemampuan sebagai antioksidan. Namun aktivitas antioksidan yang terkandung pada buah kawista masuk dalam kategori lemah (kecil). Hal ini dapat dilihat pada nilai konsentrasi pengikatan DPPH dan $\mathrm{IC}_{50}$ pada ekstrak buah kawista, yaitu sebesar $1275 \mathrm{mg} / \mathrm{ml}$, berada di atas $150 \mu \mathrm{g} / \mathrm{ml}$ (data literatur). Lemah atau kecilnya efek antioksidan dari ekstrak buah kawista yang diperoleh dikarenakan tidak terdapat senyawa asam askorbat yang berpotensi sebagai antioksidan yang sangat kuat. 


\section{KESIMPULAN}

Berdasarkan hasil nilai $\mathrm{IC}_{50}$ ekstrak buah kawista, mempunyai nilai $\mathrm{IC}_{50}$ dengan nilai 1275 ppm, yang dikategorikan lemah dalam kemampuannya sebagai antioksidan.

\section{DAFTAR PUSTAKA}

Frei, 1994, Reactive Oxygen Species and Antioxidant Vitamins: Mechanisms of Action. American Jurnal of Medicine. Excerpta Medica Inc.

Halliwel, B., 1999, Gutteridge, I. M.C. Free Radicals in Biology and Medicine. Edisi 3. Oxford University Pres: London.

$\mathrm{Ji}, \quad \mathrm{K}$, Lieu et al., 2004, DPPH Radical Scavenging Activity of Ten Natulan pTerphenyl Derivatives Obtained from Three Edible Mushrooms Indigenous to China, Chemistry and Biodiversity Vol. 1. Kunming Institute of Botani, Thess Chinese Academy of Sciences, Kunming 650204, P.R. China.

Kahkonen M.P., Hopia AI, Vourea HJ, Rauha JP, Pihlaja K, Kujala TS, Heinonen M, 1999, Antioxidant activity of extracts containing phenolic compounds, Journal of Agriculturer and Food Chemistry, 47, 39543962.

Kikuzaki H, Nakatani N., 1993, Antioxidant effects of some ginger constituents. Journal of Food Science, 58,1407-1410.

Li, P., Huo, L., W., Lu, R., Deng, C., Liu, L., Deng, Y., Guo, N., Lu, C. He, C., 2011, Free Radical Scavenging Capacity, Antioxidant Activity and Phenolic Content of (Pouzolzia zeylanica), College of Pharmacy, J. Serb. Chem. Soc., 76 (5), 709 717.

Molineux, P., 2004, The Use of The Stable Free Radical Diphenylpicrylhydrazyl (DPPH) for Estimating Antioksidan Activity, Songklanakarin J.Sci. Techol., 26 (2). 211219.
Nugroho I.A., 2012, Keragaman Morfologi dan Anatomi Kawista (Limonia acidissima L) di Kabupaten Rembang, Skripsi, Departemen Biologi, Fakultas Matematika dan Ilmu Pengetahuan Alam. Institut Pertanian Bogor. Bogor.

Prior R.L., Wu X, Schaich K., 2005, Standardized methods for the determination of antioxidant capacity and phenolics in foods and dietary supplements, Journal of Agricultural and Food Chemistry, 55, 2698 A-J.

Rohman A., Riyanto S., Utari D., 2006, Aktivitas antioksidan, kandungan fenolik total dan kandungan flavonoid total ekstrak etil asetat buah mengkudu serta fraksi-fraksinya, Majalah Farmasi Indo-nesia, 17, 136-142.

Rustiah, W., Andriani, Y., 2018, Analysis of Kelor Seed Powder (Moringa Oleifera, Lamk) in Reducing COD and BOD Levels on Wastewater Services Laundry, Indo. J. Chem Res., 5(2), 508-512.

Sayuti, K., Rina, Y., 2015, Antioksidan Alami dan Sintetik, Padang: Andalas University Press.

Sediaoetama, Djaeni, A., 2008, Vitaminologi: Bagi Umum dan Tenaga Profesi di Indonesia, Balai Pustaka Jakarta.

Tryasmono, L. Anwar, K., 2016, Kandungan Total Fenolik, Total Flavonoid, dan Aktivitas Antioksidan Ekstrak Etanol Buah Mengkudu (Morinda citrifolia L), Jurnal Pharmasaence, 8(1), 83-92.

Winarsi, H, D. Muchtadi, F.R. Zakaria, B. Purwantara, 2003, Status Antioksidan Wanita Premenoupause yang diberi Minuman Suplemen: Susumeno, Prosiding, Seminar Nasional PATPI. Yogyakarta. 